\title{
Improved Maleic Anhydride Grafting to Linear Low Density Polyethylene by Microencapsulation Method
}

\author{
Iman Rahayu ${ }^{1,}$, Achmad Zainuddin $^{1}$, and Sunit Hendrana ${ }^{2}$ \\ ${ }^{1}$ Department of Chemistry, Faculty of Mathematics and Natural Sciences, Universitas Padjadjaran, \\ Jl. Raya Bandung-Sumedang km. 21, Jatinangor, Sumedang 45363, West Java, Indonesia \\ ${ }^{2}$ Laboratory of Applied Physics, Indonesian Institute of Sciences, Jl. Sangkuriang, Kompleks LIPI, \\ Bandung 40135, West Java, Indonesia
}

${ }^{*}$ Corresponding author:

tel: $+62-89672184591$

email: iman.rahayu@unpad.ac.id

Received: August 16, 2019

Accepted: January 8, 2020

DOI: $10.22146 /$ ijc. 48785

\begin{abstract}
A common graft copolymerization method usually results in a low degree of grafting due to its poor inter-component interactions. A monomer microencapsulation method should be useful to enhance the current graft copolymerization technique. The maleic anhydride (MAH) grafted with linear low-density polyethylene (LLDPE) was successfully synthesized by monomer microencapsulation without using a direct method in order to find a high degree of grafting. The results showed that the degree of grafting of the LLDPE synthesized by microencapsulation (5.9\%) was higher than that achieved with the direct method (5.0\%).
\end{abstract}

Keywords: grafting; LLDPE; maleic anhydride; microencapsulation

\section{- INTRODUCTION}

The functionalization of polyolefin can increase its chemical and physical properties, leading to its wider application. Several methods that are widely used for functionalization are blending [1], surface treatment [2], and grafting [3-6]. There are several known types of the latter method, namely grafting in the aqueous phase [7], ultrasonic initiation [8], solid phase, photoionization [9], and free radical in the melting phase [10]. Among those methods, grafting by free radical in the melting phase using a polar monomer is one of the most frequently applied techniques due to its potential and wide applications [10-12].

To best of our knowledge, the functionalization of polyolefin through the free radical copolymerization by maleic anhydride (MAH) as the polar monomer is very popular in commercial applications due to its high activity $[10,13-14]$. The use of MAH in the grafting process is preferable since it produces small oligomers, and no homopolymerization occurs [15-16]. Polyethylene-graftmaleic anhydride (PE-g-MAH) has been commercially used as fiberglass, anti-corrosive coating for metal pipes, paper for food containers, adhesives, and is compatible as
PE for polar polymers such as polyamide and polyester [13,17-19].

The functionalization of MAH to polyolefin is conducted to homogenize the graft reactions of MAHpolyolefin with a high degree of grafting. This method is used to avoid the non-favorable side-product resulting from crosslink and chain-breaking reactions [10]. Rosales et al. investigated the graft of LLDPE with diethyl maleate (DEM) in different extrusion conditions, which resulted in a maximum degree of grafting at 0.5 moles [14]. Moreover, the grafting degree (GD) of LLDPE-g-MAH by ultrasonic initiator was $0.54 \%$ [8]. So far, the grafting process using $\mathrm{MAH}$ remains unsatisfactory, as indicated by the low grafting degree and heterogeneous functionalization of the chemical group. To overcome this problem, several techniques have been developed through the modification of the monomer, initiator, and synthesis method or graft copolymerization. The graft copolymerization of MAH to the LDDPE using the monomer microencapsulation method is a relatively new approach. Theoretically, it is based on the directed-diffusion of the termination step where monomer molecules are trapped inside the pore 
of the polymer. Thus, the closer segmental-diffusion would improve the interaction between the polymer and the monomer.

In the present study, the graft copolymerization of MAH to LLDPE using the monomer microencapsulation method was developed and compared to the direct method. The grafting degree in the process of graft copolymerization of MAH to the polyolefin was also investigated. This study was aimed to synthesize the maleic anhydride (MAH) grafted with low-density polyethylene (LLDPE) using the monomer microencapsulation method and to determine its degree of grafting and crosslink.

\section{- EXPERIMENTAL SECTION}

\section{Materials}

The materials used in this study included LLDPE (melt flow rate (MFR) 1 g. $10 \mathrm{~min}^{-1}$ and $\rho=0.920$ g.cm ${ }^{-3}$ ) from Bassel, Inc., Indonesia, dicumyl peroxide/DCP (Aldrich), acetone (Merck), chloroform (Merk), maleic anhydride (Merk, p.a grade), and xylene (Merk, p.a grade).

\section{Instrumentation}

The instruments employed in this experiment involved Oven 6PHP-200 (Tabai), Haake Reomix 600p Roller Rotors R600, analytical balance, vacuum oven DP 33 (Yamato), soxhlet extraction apparatus, hot and pressure (Gonno), MFR (Dynisco Polymer Test), FT-IR spectrophotometer (Perkin Elmer), Nuclear Magnetic Resonance (Bruker Avance III $300 \mathrm{MHz}$ ), Differential Scanning Calorimetry (Mettler Toledo 1 Star), and Thermal Gravimetric Analysis (Mettler Toledo 1 Star).

\section{Procedure}

\section{Synthesis of LLDPE by monomer microencapsulation}

To a container holding $2 \mathrm{~kg}$ LLDPE (MFR $1 \mathrm{~g} / 10 \mathrm{~min}$ and density $\left.0.920 \mathrm{~g}^{\mathrm{cm}} \mathrm{cm}^{-3}\right), 100 \mathrm{~mL}$ of $5 \% \mathrm{MAH}$ in acetone was added. The mixture was mixed thoroughly, and the container tightly closed. It was opened and stirred to evaporate the acetone every day for a week. Furthermore, the process was continued until 6 days in, at which point came the addition of $100 \mathrm{~mL}$ of $10 \% \mathrm{MAH}$ in acetone. The sample was homogenized weekly for six months. Successful microencapsulation is indicated by a cloudy solution. The microencapsulated polymer was named mLLDPE.

\section{Synthesis of mLLDPE-g-MAH and LLDPE-g-MAH}

To a mixing container, $50 \mathrm{~g}$ of mLLDPE and DCP, as an initiator with a concentration of $40 \% \mathrm{~mol}$, was added and blended using Haake Rheomix 600p at $200^{\circ} \mathrm{C}$ and a mixing speed of $40,60,80$, and $100 \mathrm{rpm}$ for $4 \mathrm{~min}$. During the blending, the torsion value was recorded over time. Torsion is defined as the energy of rotation $(\mathrm{Nm})$, which is used throughout the polymer blending process.

\section{Analysis of grafting degree of LLDPE-g-MAH using titration}

The sample was refluxed with xylene for $30 \mathrm{~min}$ before the temperature was lowered to $80^{\circ} \mathrm{C}$, which was followed by the addition of $0.2 \mathrm{M}$ potassium hydroxide in ethanol. Reflux was carried out for another $15 \mathrm{~min}$. Phenolphthalein was added to the reflux product, followed by the titration using $0.2 \mathrm{M}$ of hydrochloric acid/isopropyl alcohol until the color changed from magenta to colorless. The grafting degree was calculated from the volume of hydrochloric acid/isopropyl employed in titration using Eq. (1) [7].

$\mathrm{GD}(\%$ mass $)=\frac{\mathrm{N}\left(\mathrm{V}_{\mathrm{o}}-\mathrm{V}\right) \times 98.06}{2000 \mathrm{~W}} \times 100 \%$

$\mathrm{N}$ = concentration of $\mathrm{HCl} /$ isopropyl alcohol $\left(\mathrm{mol}_{\mathrm{L}} \mathrm{L}^{-1}\right)$

$\mathrm{V}_{\mathrm{o}}=$ volume of $\mathrm{HCl} /$ isopropyl alcohol used as a blank $(\mathrm{mL})$

$\mathrm{V}=$ volume of $\mathrm{HCl} /$ isopropyl alcohol used in titration $(\mathrm{mL})$

$\mathrm{W}=$ mass of sample $(\mathrm{g})$

98.06 = relative molecular mass of MAH

\section{- RESULTS AND DISCUSSION}

\section{Synthesis and Characterization of Grafted LLDPE}

The change of torsion during the blending process using $40 \%$ of DCP at $80 \mathrm{rpm}$ rotation rate indicated the different interactions of mLLDPE-g-MAH and LLDPEg-MAH (Fig. 1). An obvious change of torsion between mLLDPE-g-MAH and LLDPE-g-MAH was observed from 0.3 up to $0.4 \mathrm{~min}$, indicated by a sharp change of torsion value. At the beginning of the reaction, the first peak showed that the plasticization of LLDPE had occurred [10]. 


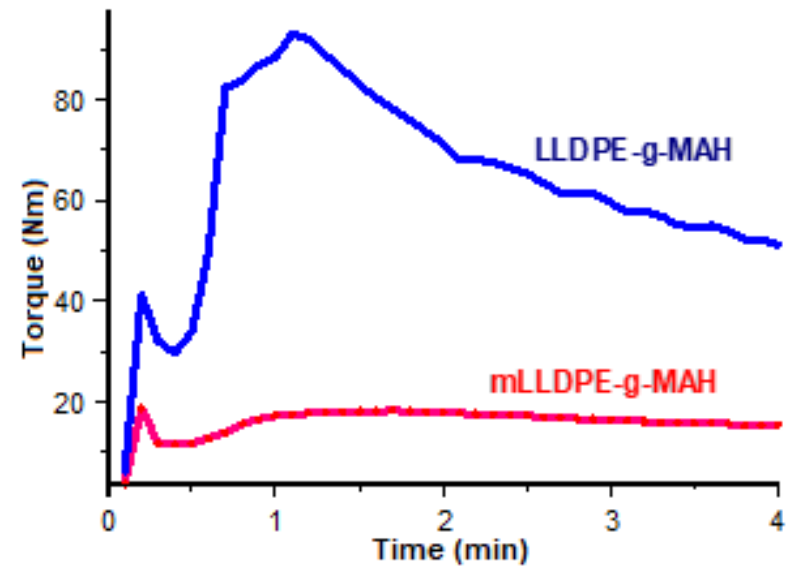

Fig 1. The plot of torsion over time for samples of mLLDPE-g-MAH and LLDPE-g-MAH (fabricated using $40 \%$ of DCP at $80 \mathrm{rpm}$ rotation rate)

The second maximum peak or "cure peak" from LLDPE-g-MAH was higher than that of mLLDPE-gMAH. This peak is known to be related to the viscosity [20]. Therefore, the high peak of LLDPE-g-MAH is indicating the formation of crosslinks within the sample. The results were supported by the torsion data (Fig. 1), where the torsion of mLLDPE-g-MAH was stable under $20 \mathrm{Nm}$, while that of LLDPE-g-MAH reached $50 \mathrm{Nm}$. Thus, it is suggested that the monomer encapsulation method could decrease the occurrence of the crosslink. The reason behind this observation is related to the theory of directed-diffusion, in which the polymer-monomer interaction is independent of the reactivity, but affected by the distance or physical interaction between the two. After the diffusion-translation occurred between the two propagated radicals, the diffusion-segmental between radicals of the polymer and monomer took place. Lastly, the chemical interaction between radicals would result in graft copolymerization of the monomer to the polymer.

Further evidence of the occurrence of crosslink in
LLDPE-g-MAH is presented in Table 1. The MFR value of mLLDPE-g-MAH was higher than LLDPE-g-MAH, which was immeasurable. A higher value of MFR reflects low viscosity of the sample, and hence it is diluted and flows easily [20]. In fact, LLDPE-g-MAH did not flow easily, indicating the gel formation due to the crosslink reaction. A high number of crosslinks in LLDPE-gMAH is shown by the result of Soxhlet extraction (Table 1). The higher quantity of crosslinks in LLDPE-g-MAH was predicted to be formed at the "cure peak" (Fig. 1). This observation is in agreement with the theory of the mechanism of directed-diffusion. In a thick liquid, the reaction between polymer radicals is higher than the reaction between radicals of polymer and $\mathrm{MAH}$, thus increasing the number of crosslinks in the product. Several analyses were performed to provide a better explanation of this phenomenon.

Fig. 2 shows the FT-IR spectra of mLLDPE-gMAH and LLDPE-g-MAH after the extraction with acetone. The presence of maleic anhydride, which is attached to the LLDPE, is confirmed by the absorbance at wavenumber of 1720 and $1780 \mathrm{~cm}^{-1}$ for $\mathrm{C}=\mathrm{O}$ stretching; at $1260 \mathrm{~cm}^{-1}$ for asymmetrical C-O-C stretching, and at $960 \mathrm{~cm}^{-1}$ for five-membered ring anhydride stretching [16].

Fig. 3 shows the FTIR spectra of the soluble fractions of mLLDPE-g-MAH and LLDPE-g-MAH. The successful maleation process is confirmed by the peaks at wavenumber between 1700 and $1800 \mathrm{~cm}^{-1}$, i.e., 1720 and $1780 \mathrm{~cm}^{-1}$. These absorptions are higher in mLLDPE-g-MAH than those in LLDPE-g-MAH. It indicates that the formation of succinic anhydride was higher than the maleic anhydride. However, the gel fraction showed a contrast result compared to the soluble fraction (Fig. 4).

Table 1. Values of MFR, monomer conversion, gel fraction, and grafting degree of mLLDPE-g-MAH and LLDPE-gMAH (at $40 \%$ of DCP and $80 \mathrm{rpm}$ rotation rate)

\begin{tabular}{lcc}
\hline \multicolumn{1}{c}{ Parameter } & mLLDPE-g-MAH & LLDPE-g-MAH \\
\hline MFR (g/10 min) & 0.89 & Not detected \\
Monomer conversion (\%) & 59.7 & 53.3 \\
Gel fraction (\%) & 68.3 & 79.8 \\
Grafting degree (\%) & 5.92 & 4.98 \\
\hline
\end{tabular}




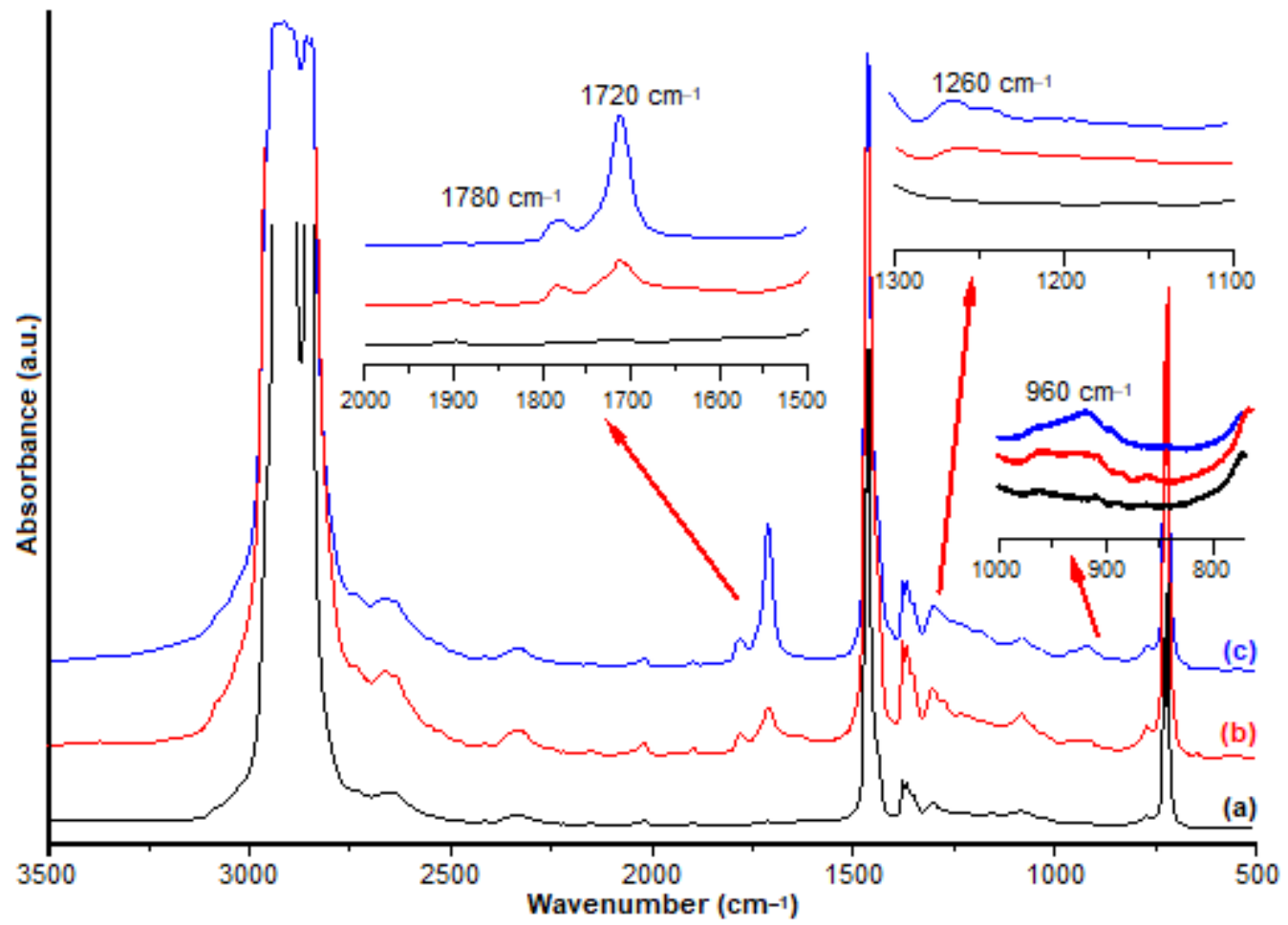

Fig 2. The FTIR spectra of acetone extract of (a) LLDPE, (b) mLLDPE-g-MAH, and (c) LLDPE-g-MAH (fabricated using $40 \%$ of DCP at $80 \mathrm{rpm}$ rotation rate)

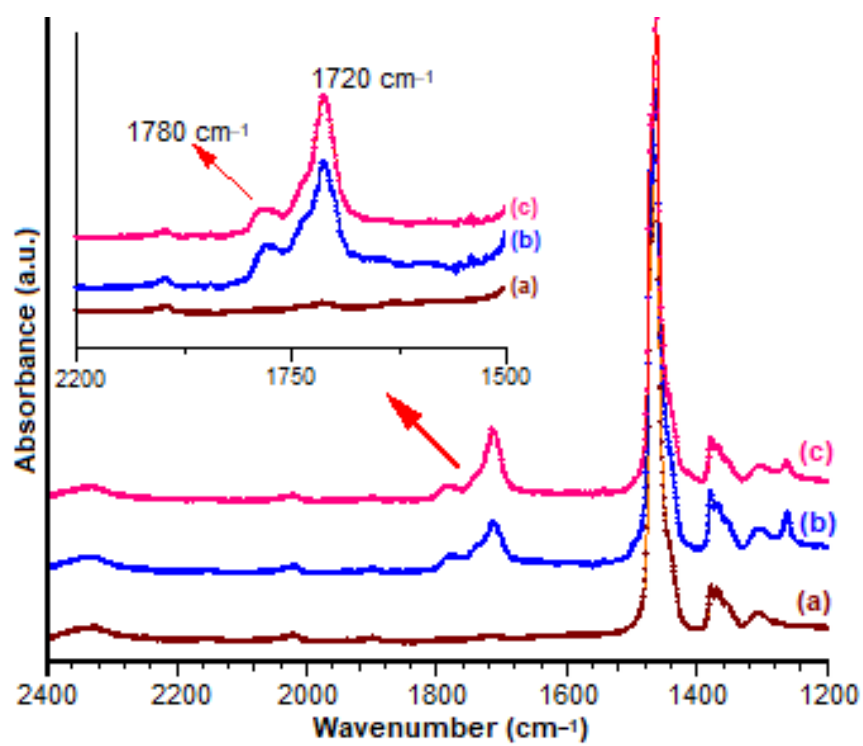

Fig 3. FTIR spectra of xylene soluble fraction extract of (a) LLDPE, (b) mLLDPE-g-MAH, and (c) LLDPE-g-MAH (fabricated using $40 \%$ of DCP at $80 \mathrm{rpm}$ rotation rate)

\section{Thermal Properties}

The DSC thermogram of glass transition temperature $(\mathrm{Tg})$ and melting point $(\mathrm{Tm})$ from both soluble and gel fractions

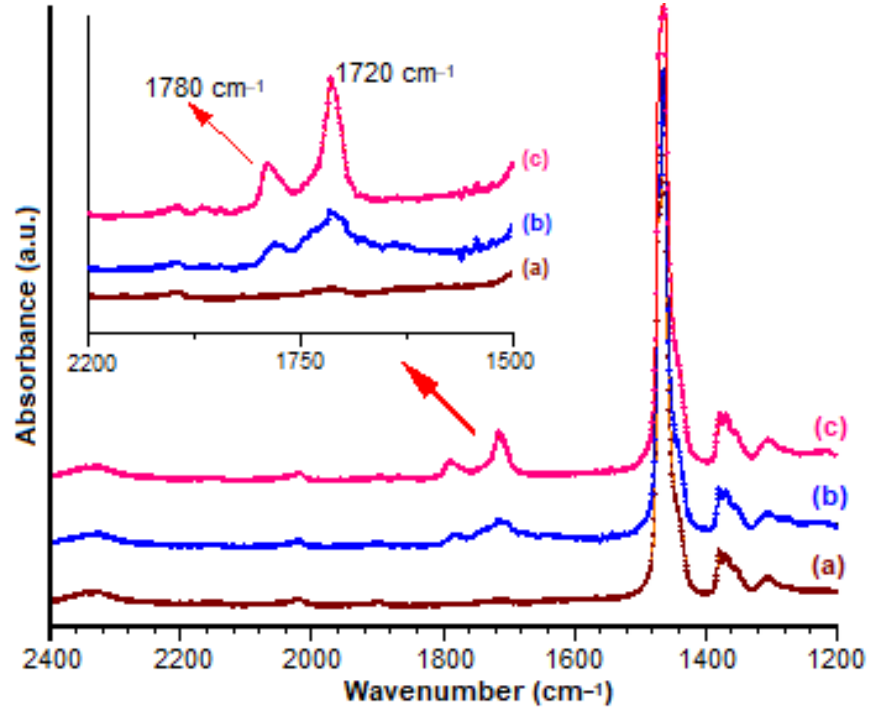

Fig 4. FTIR spectra of xylene extract gel fraction of (a) LLDPE, (b) mLLDPE-g-MAH, and (c) LLDPE-g-MAH (fabricated using $40 \%$ of DCP at $80 \mathrm{rpm}$ rotation rate)

of mLLDPE-g-MAH and LLDPE-g-MAH are shown in Fig. 5. Fig. 5 and Table 2 illustrate that in both fractions, the Tg of mLLDPE-g-MAH is higher than that of 
LLDPE-g-MAH. In the soluble fraction, the Tm of mLLDPE-g-MAH is lower than that of LLDPE-g-MAH, while in the gel fraction mLLDPE-g-MAH has a higher value. The presence of $\mathrm{MAH}$ and gel formation in the polymer lead to sturdier material, and lower crystallinity and $\operatorname{Tm}[21]$.

Fig. 5 shows the gel fraction of the LLDPE samples, as indicated by the width of the DSC thermogram. In general, there are no significant differences in $\mathrm{Tg}$, Tm, and Tc values. However, the thermogram of the gel fraction of LLDPE-g-MAH shows a wide endothermic absorption.

Fig. 6 shows the DSC thermogram of the crystallization temperature (Tc) of mLLDPE-g-MAH and LLDPE-g-MAH in both fractions. Tc values are shown in Table 2. The Tc of the soluble fraction of mLLDPE-gMAH is higher than that of LLDPE-g-MAH, while the Tc values of both samples in the gel fraction are similar. The presence of $\mathrm{MAH}$ and gel formation increase the rigidity of polymer, decrease the mobility of the chain, lower the crystallinity, and eventually increase the Tc value.

Fig. 7 shows the TGA thermogram of mLLDPE-g$\mathrm{MAH}$ and LLDPE-g-MAH in both fractions in the range of decomposition temperature from 300 to $550{ }^{\circ} \mathrm{C}$. To observe a clearer change of decomposition percentage, a first derivative of the decomposition thermogram is

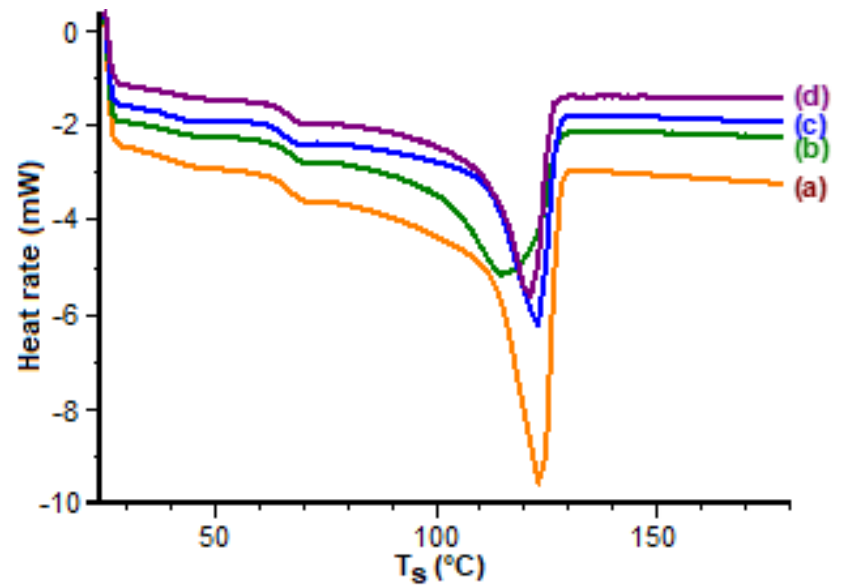

Fig 5. DSC thermogram of (a) mLLDPE-g-MAH gel fraction, (b) LLDPE-g-MAH gel fraction, (c) mLLDPE-gMAH soluble fraction, and (d) LLDPE-g-MAH soluble fraction (fabricated using $40 \%$ of DCP at $80 \mathrm{rpm}$ rotation rate) drawn and is presented in Fig. 8. It is clear that the gradients of mLLDPE-g-MAH and LLDPE-g-MAH in the soluble fractions changed between 200 and $350{ }^{\circ} \mathrm{C}$, whereas both samples in the gel fractions are not. Interestingly, the decomposition of mLLDPE-g-MAH in the soluble fraction is faster than the decompositions in the other samples. This might be related to the noncarbon decomposition, which probably derived from the maleic anhydride group.

Table 3 shows that between 325 and $425^{\circ} \mathrm{C}$, the percentage decomposition of mLLDPE-g-MAH in both fractions is higher than that of the LLDPE-g-MAH. Meanwhile, at $425^{\circ} \mathrm{C}$, decomposition of the gel fraction of mLLDPE-g-MAH is smaller than that of the LLDPEg-MAH. We then compared this to the Tc of LLDPE

Table 2. Values of Tg, Tm, and Tc of the gel fractions (g) and solvated fractions (s) of mLLDPE-g-MAH and LLDPE-g-MAH (fabricated using $40 \%$ of DCP at $80 \mathrm{rpm}$ rotation rate)

\begin{tabular}{llcc}
\hline \multicolumn{1}{c}{ Sample } & $\mathrm{Tg}\left({ }^{\circ} \mathrm{C}\right)$ & $\mathrm{Tm}\left({ }^{\circ} \mathrm{C}\right)$ & $\mathrm{Tc}\left({ }^{\circ} \mathrm{C}\right)$ \\
\hline LLDPE-g-MAH $(\mathbf{g})$ & 64 & 118 & 107 \\
mLLDPE-g-MAH (g) & 65 & 122 & 107 \\
LLDPE-g-MAH (s) & 65 & 122 & 105 \\
mLLDPE-g-MAH (s) & 65.5 & 122 & 107 \\
\hline
\end{tabular}

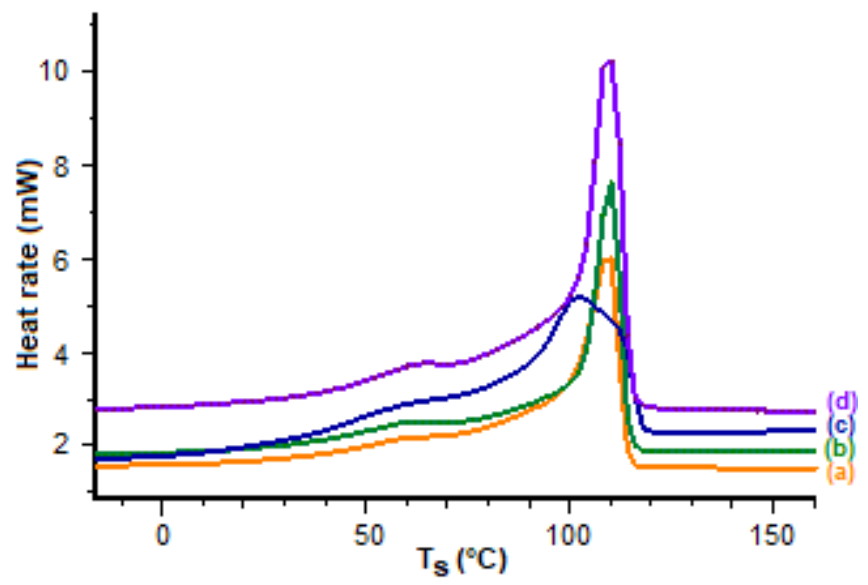

Fig 6. DSC thermogram of Tc of solvated fractions of (a) LLDPE-g-MAH, (b) mLLDPE-g-MAH, and gel fractions of (c) LLDPE-g-MAH, (d) mLLDPE-g-MAH (fabricated using $40 \%$ of DCP at $80 \mathrm{rpm}$ rotation rate) 


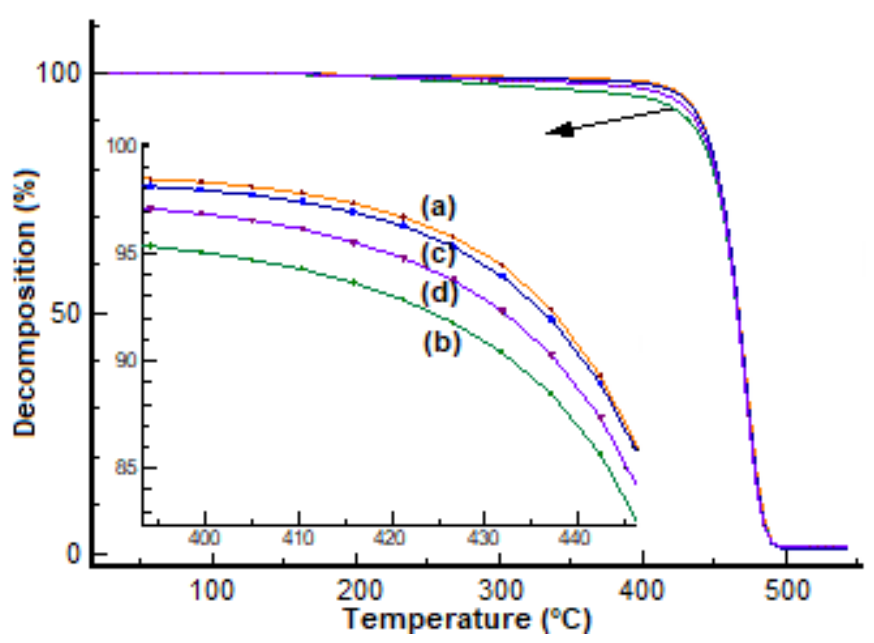

Fig 7. TGA thermogram of the soluble fractions of (a) mLLDPE-g-MAH, (b) LLDPE-g-MAH, and gel fractions of (c) mLLDPE-g-MAH, (d) LLDPE-g-MAH (fabricated using $40 \%$ of DCP at $80 \mathrm{rpm}$ rotation rate)

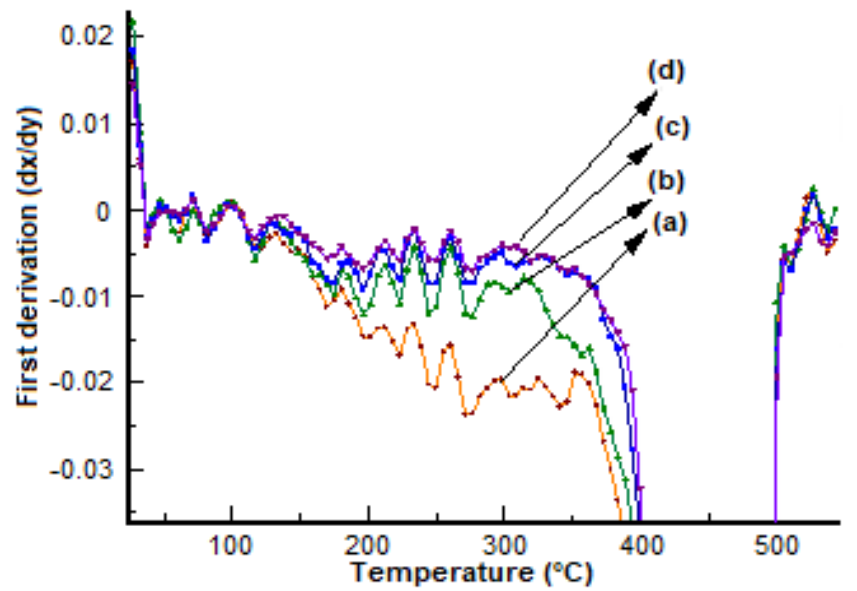

Fig 8. The first derivate of the TGA thermogram of samples decomposition of the soluble fractions: (a) mLLDPE-g-MAH (b) LLDPE-g-MAH, and that of gel fractions: (c) mLLDPE-g-MAH, (d) LLDPE-g-MAH (fabricated using $40 \%$ of DCP at $80 \mathrm{rpm}$ rotation rate)

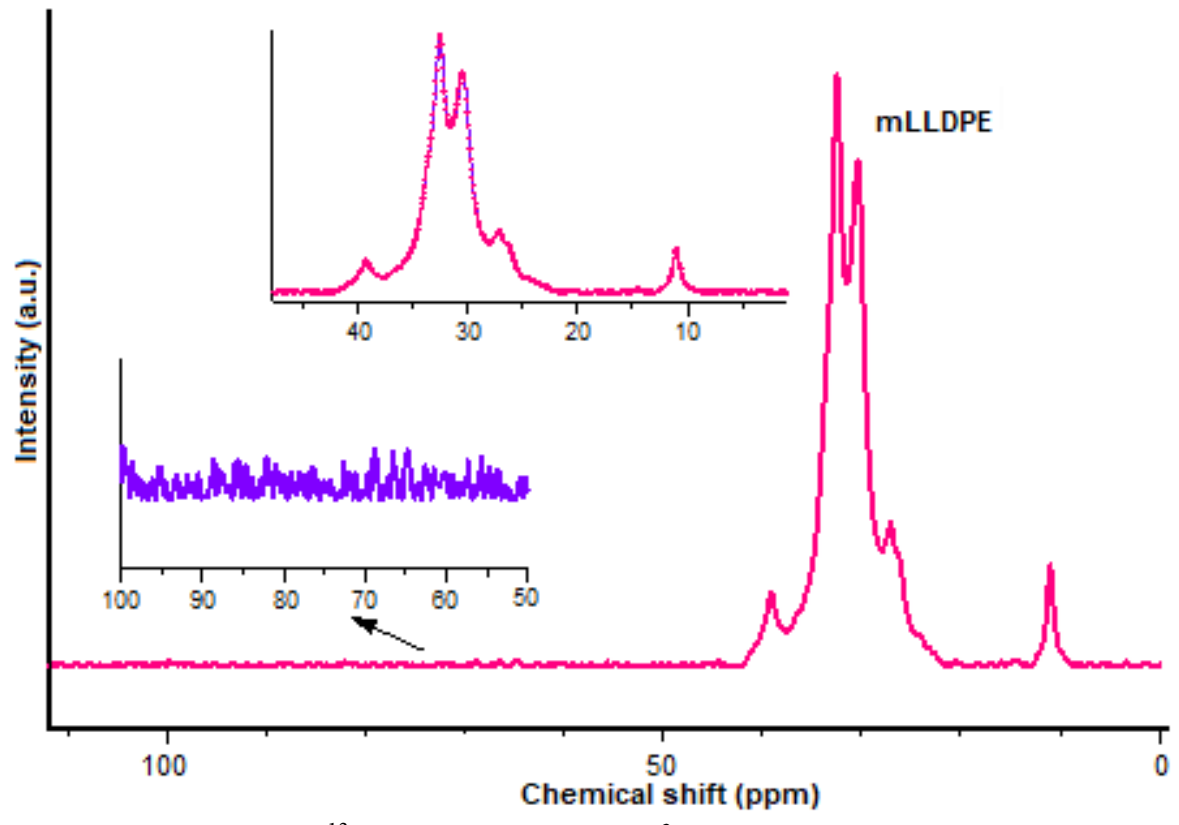

Fig 9. ${ }^{13} \mathrm{C}-\mathrm{NMR}$ spectrum of mLLDPE-g-MAH

based on the reference, which shows a TG value of $360^{\circ} \mathrm{C}$. The Tc of LLDPE-g-MAH is much higher than the Tc of irradiated and non-irradiated LLDPE, which shows a range value of 380 to $340{ }^{\circ} \mathrm{C}$ [21].

The decomposition between 325 and $425{ }^{\circ} \mathrm{C}$ indicates the removal of MAH from the LLDPE. The high decomposition percentage corresponded to the high number of MAH that were attached to the LLDPE. After
$425{ }^{\circ} \mathrm{C}$, the mass decreased due to the removal of the attached group, which mostly derived from the backbone of LLDPE. As can be seen in the diagram, LLDPE was completely decomposed after $550{ }^{\circ} \mathrm{C}$. It is suggested that the number of MAH that attached to the microencapsulated sample was higher than the LLDPEg-MAH. To confirm the MAH attached to LLDPE, the NMR analysis was deployed. 
Table 3. Percentage decomposition of mLLDPE-g-MAH and LLDPE-g-MAH in the soluble fraction (s), and gel fraction (g) (fabricated using $40 \%$ of DCP at $80 \mathrm{rpm}$ rotation rate)

\begin{tabular}{lcc}
\hline \multirow{2}{*}{ Sample } & \multicolumn{2}{c}{ Percentage of decomposition (\%) } \\
\cline { 2 - 3 } & $325^{\circ} \mathrm{C}$ & $425^{\circ} \mathrm{C}$ \\
\hline LLDPE-g-MAH (g) & 0.88 & 4.21 \\
mLLDPE-g-MAH (g) & 1.14 & 4.64 \\
LLDPE-g-MAH (s) & 1.58 & 6.22 \\
mLLDPE-g-MAH (s) & 2.93 & 8.21 \\
\hline
\end{tabular}

Table 4. Chemical shift and predicted carbon type/functional group of mLLDPE-g-MAH

Chemical shift (ppm)

The ${ }^{13} \mathrm{C}-\mathrm{NMR}$ was used to determine the structure of MAH that attached to the LLDPE structure (Fig. 9).
Each chemical shift represents the carbon type from a particular functional group. The interpretations of each chemical shift are presented in Table 4 [22].

It is noted that the intensity of the chemical shift at $173 \mathrm{ppm}$ indicates succinic anhydride. This result signifies that the number of MAH attached to the LDDPE is higher in the form of succinic anhydride than $\mathrm{MAH}$. This result is also supported by the presence of a chemical shift at $28.6 \mathrm{ppm}$, which showed the $\left(\mathrm{CH}_{2}\right)$ from succinic anhydride.

\section{- CONCLUSION}

The graft copolymerization of MAH to LLDPE using monomer microencapsulation and DCP as initiator increase the grafting degree compared to the direct method. The product of the monomer microencapsulation method, mLLDPE-g-MAH, has a grafting degree of $5.9 \%$, while that of the direct method has a $5.0 \%$ degree. The microencapsulation process improves the $\mathrm{Tg}, \mathrm{Tm}$, and $\mathrm{Tc}$ of mLLDPE-g-MAH compared to the direct method based on DSC analysis. We suggest that the microencapsulation could be a novel method in the polymerization process to attach MAH to LLDPE, which can increase the degree of grafting to enhance the physical properties of LLDPE.

\section{- ACKNOWLEDGMENTS}

This work was partially funded by the Indonesian Institute of Sciences through the Program Unggulan LIPI and I-MHERE project for Universitas Padjadjaran from the Directorate General of Higher Education, Ministry of National Education Republic of Indonesia. Characterization by DSC and TGA from the Australian Institute for Bioengineering and Nanomaterials (AIBN), University of Queensland, Brisbane Australia. Therefore, we would like to acknowledge their support.

\section{- REFERENCES}

[1] Valente, T., Ferreira, J.L., Henriques, C., Borges, J.P., and Silva, J.C. 2019, Polymer blending or fiber blending: A comparative study using chitosan and poly ( $\varepsilon$-caprolactone) electrospun fibers, J. Appl. Polym. Sci., 136 (1), 47191. 
[2] Sato, A., Kabusaki, D., Okumura, H., Nakatani, T., Nakatsubo, F., and Yano, H. 2016, Surface modification of cellulose nanofibers with alkenyl succinic anhydride for high-density polyethylene reinforcement, Compos. Part A Appl. Sci. Manuf., 83, 72-79.

[3] Wang, W., Zhang, X., Mao, Z., and Zhao, W., 2019, Effects of gamma radiation on the impact strength of polypropylene (PP)/high density polyethylene (HDPE) blends, Results Phys., 12, 2169-2174.

[4] Khani, M.M., Woo, D., Mumpower, E.L., and Benicewicz, B.C., 2017, Poly (alkyl methacrylate)grafted silica nanoparticles in polyethylene nanocomposites, Polymer, 109, 339-348.

[5] Khanoonkon, N., Yoksan, R., and Ogale, A.A., 2016, Effect of stearic acid-grafted starch compatibilizer on properties of linear low density polyethylene/ thermoplastic starch blown film, Carbohydr. Polym., 137, 165-173.

[6] Mandal, D.K., Bhunia, H., Bajpai, P.K., and Bhalla, V.K., 2017, Thermal degradation kinetics and estimation of lifetime of radiation grafted polypropylene films, Radiat. Phys. Chem., 136, 1-8.

[7] Campos, P.G.S., Fantini, M.C.A., and Petri, D.F.S., 2004, Grafting of tetrahydrophthalic and maleic anhydride onto polyolefins in solution, J. Braz. Chem. Soc., 15 (4), 532-540.

[8] Zhang, Y., Chen, J., and Li, H., 2006, Functionalization of polyolefins with maleic anhydride in melt state through ultrasonic initiation, Polymer, 47 (13), 47504759.

[9] Deng, J.P., and Yang, W.T., 2001, Self-initiating performance of maleic anhydride on surface photografting polymerization, J. Polym. Sci., Part A: Polym. Chem., 39 (19), 3246-3249.

[10] Aghjeh, M.K.R., Nazockdast, H., and Assempour, H., 2006, Parameters affecting the free-radical melt grafting of maleic anhydride onto linear low-density polyethylene in an internal mixer, J. Appl. Polym. Sci., 99 (1), 141-149.

[11] Chang, M.K., 2015, Mechanical properties and thermal stability of low-density polyethylene grafted maleic anhydride/montmorillonite nanocomposites, J. Ind. Eng. Chem., 27, 96-101.

[12] Kahar, A.W.M., Ismail, H., and Othman, N., 2012, Effects of polyethylene-grafted maleic anhydride as a compatibilizer on the morphology and tensile properties of (thermoplastic tapioca starch)/(highdensity polyethylene)/(natural rubber) blends, $J$. Vinyl Add. Tech., 18 (1), 65-70.

[13] Majid, R.A., Ismail, H., and Taib, R.M., 2010, Effects of polyethylene-g-maleic anhydride on properties of low density polyethylene/ thermoplastic sago starch reinforced kenaf fibre composites, Iran. Polym. J., 19 (7), 501-510.

[14] Jantanasakulwong, K., Leksawasdi, N., Seesuriyachan, P., Wongsuriyasak, S., Techapun, C., and Ougizawa, T., 2016, Reactive blending of thermoplastic starch and polyethylene-graft-maleic anhydride with chitosan as compatibilizer, Carbohydr. Polym., 153, 89-95.

[15] Roumeli, E., Terzopoulou, Z., Pavlidou, E., Chrissafis, K., Papadopoulou, E., Athanasiadou, E., Triantafyllidis, K., and Bikiaris, D.N., 2015, Effect of maleic anhydride on the mechanical and thermal properties of hemp/high-density polyethylene green composites, J. Therm. Anal. Calorim., 121, 93-105.

[16] Saini, A., Yadav, C., Bera, M., Gupta, P., and Maji, P.K., 2017, Maleic anhydride grafted linear lowdensity polyethylene/waste paper powder composites with superior mechanical behavior, $J$. Appl. Polym. Sci., 134 (31), 45167.

[17] Colbeaux, A., Fenouillot, F., Gérard, J.F., Taha, M., and Wautier, H., 2005, Compatibilization of a polyolefin blend through covalent and ionic coupling of grafted polypropylene and polyethylene. I. Rheological, thermal, and mechanical properties, J. Appl. Polym. Sci., 95 (2), 312-320.

[18] Guzmán, M., and Murillo, E.A., 2015, The properties of blends of maleic-anhydride-grafted polyethylene and thermoplastic starch using hyperbranched polyester polyol as a plasticizer, Polym. Eng. Sci., 55 (11), 2526-2533. 
[19] Hernandez-Ortiz, J., Van Steenberge, P.H.M., Duchateau, J.N., Toloza, C., Schreurs, F., Reyniers, M.F., Marin, G.B., and D'hooge, D.R., 2019, A multiscal tool for functionalization of polyolefins through radical grafting, Autex 2019 -The $19^{\text {th }}$ World Textile Conference on Textiles at the Crossroads, 11-15 June 2019, Ghent, Belgium.

[20] Oliveira, A.C.F., Parra, D.F., Ferreto, H.F.R., and Lugão, A.B., 2013 Characterization of injected linear low density polyethylene (LLDPE) irradiated by gamma-ray, The $6^{\text {th }}$ International Nuclear Atlantic
Conference - INAC 2013, 24-29 November 2013, Recife, Brazil.

[21] Saade-Caballero, H., and Martínez-Colunga, J.G., 2009, Reactive extrusion process for the grafting of maleic anhydride onto linear low-density polyethylene with ultraviolet radiation, J. Appl. Polym. Sci., 113 (5), 3125-3129.

[22] Dartora, P.C., Marlene, R., Santana, C., Cristina, A., and Moreira, F., 2015, The influence of long chain branches of LLDPE on processability and physical properties, Polimeros, 25 (6), 531-539. 